\title{
De novo transcriptome analysis of Hevea brasiliensis tissues by RNA-seq and screening for molecular markers
}

\author{
Leonardo Rippel Salgado 1*, Daniela Martins Koop², Daniel Guariz Pinheiro ${ }^{1}$, Ronan Rivallan³ ${ }^{3}$ Vincent Le Guen³, \\ Marisa Fabiana Nicolás ${ }^{4}$, Luiz Gonzaga Paula de Almeida ${ }^{4}$, Viviani Ribeiro Rocha ${ }^{4}$, Milena Magalhães ${ }^{4}$, \\ Alexandra Lehmkuhl Gerber ${ }^{4}$, Antonio Figueira ${ }^{5}$, Júlio Cézar de Mattos Cascardo ${ }^{2 \wedge}$, AnaTereza Ribeiro de Vasconcelos ${ }^{4}$, \\ Wilson Araújo Silva Jr', Luiz Lehmann Coutinho ${ }^{6}$ and Dominique Garcia ${ }^{3 *}$
}

\begin{abstract}
Background: The rubber tree, Hevea brasiliensis, is a species native to the Brazilian Amazon region and it supplies almost all the world's natural rubber, a strategic raw material for a variety of products. One of the major challenges for developing rubber tree plantations is adapting the plant to biotic and abiotic stress. Transcriptome analysis is one of the main approaches for identifying the complete set of active genes in a cell or tissue for a specific developmental stage or physiological condition.

Results: Here, we report on the sequencing, assembling, annotation and screening for molecular markers from a pool of $\mathrm{H}$. brasiliensis tissues. A total of 17,166 contigs were successfully annotated. Then, 2,191 Single Nucleotide Variation (SNV) and 1.397 Simple Sequence Repeat (SSR) loci were discriminated from the sequences. From 306 putative, mainly non-synonymous SNVs located in CDS sequences, 191 were checked for their ability to characterize 23 Hevea genotypes by an allele-specific amplification technology. For 172 (90\%), the nucleotide variation at the predicted genomic location was confirmed, thus validating the different steps from sequencing to the in silico detection of the SNVs.
\end{abstract}

Conclusions: This is the first study of the $\mathrm{H}$. brasiliensis transcriptome, covering a wide range of tissues and organs, leading to the production of the first developed SNP markers. This process could be amplified to a larger set of in silico detected SNVs in expressed genes in order to increase the marker density in available and future genetic maps. The results obtained in this study will contribute to the $H$. brasiliensis genetic breeding program focused on improving of disease resistance and latex yield.

Keywords: Next generation sequencing, Molecular markers, KASP genotyping chemistry, Rubber tree

\section{Background}

Hevea brasiliensis (Wild.) Muell.-Arg. is a tree native to the Brazilian Amazon region and it is botanically classified in the Angiospermae division, class Dicotyledoneae, and family Euphorbiaceae. Many species from the Euphorbiaceae

\footnotetext{
*Correspondence: Irippel@usp.br; dominique.garcia@cirad.fr

Deceased

'Departamento de Genética/FMRP/USP, Laboratório de Genética Molecular e Bioinformática, Rua Tenente Catão Roxo, 2501, CEP 14.051- 140 Ribeirão

Preto, São Paulo, Brazil

${ }^{3}$ CIRAD, BIOS, UMR-AGAP, TA A96/03, Av. Agropolis, 34398 Montpellier, France

Full list of author information is available at the end of the article
}

produce latex in specialized cells (laticifers). In the case of $H$. brasiliensis, the latex is a stable emulsion of isoprenoid polymers widely employed to produce natural rubber. In the Amazon, the population of $H$. brasiliensis is estimated to be one of the twenty most abundant tree species [1]. Hevea brasiliensis is also the most abundant specie of the genus, with the largest production capacity, accounting for about $99 \%$ of all natural rubber produced in the world, and with the greatest genetic variability [2]. Natural rubber is a strategic natural raw material used in more than 40,000 industrial products, including 400 medical devices [3]. Due to its structure and high molecular weight $(>1$ million

\section{Biomed Central}


Dalton), natural rubber presents special features such as resilience, elasticity, resistance to abrasion and impact, which cannot be achieved by synthetic polymers [4]. Increased demand for natural rubber on the international market and, consequently, the strengthening of the price, has promoted the rubber cultivation, placing rubber production within the range of highly attractive options available [5].

One of the major challenges for rubber tree cultivation is its adaptation to biotic and abiotic stress. In areas with a notable dry season and low mean temperatures, rubber cultivation is characterized by a long period of immaturity. In tropical regions of Latin America where the high level of relative humidity might be more suitable for rubber development, the climatic conditions are also conducive to the infection of rubber tree leaves by the fungus Microcyclus ulei, the causal agent of the South American Leaf Blight. Repeated attacks of this disease cause massive losses of leaves, leading to plant death. The main strategies proposed for avoiding the $M$. ulei damage in plantations involve cultivating genotypes tolerant for dryness and cold in sub-optimal areas and promoting new SALB-resistant and productive cultivars in tropical areas [6]. One of the measures for avoiding M. ulei infection takes advantage of the strict high temperature and air humidity conditions for the fungus to reproduce. Based on this requirement, two infection avoidance strategies can be proposed: climatic escape, where leaf exchanges occur during the dry season, when weather conditions are not favorable to fungal sporulation or growing rubber trees in sub-optimal areas (with lower average temperatures and air humidity). Both approaches inhibit $M$. ulei infection, but also may reduce rubber tree yield. The important factor for rubber cultivation is the vegetative fitness of the tree, which is directly reflected in the genetic potential of the cultivated clone [7]. The RRIM600 Oriental clone is classified as susceptible to SALB, and highly productive over a range of temperatures and relative humidity.

Breeding between inbreeds with different characteristics targeting tolerance of biotic and abiotic stress has been identified as an alternative for improving rubber tree growth and production. Overcoming such challenges can be assisted through the development of new strategies and tools in the biotechnology field. Of those tools, we can highlight sequencing of the expressed genome of $H$. brasiliensis (transcriptome), representing the complete set and quantity of transcripts in a cell or tissue for a specific developmental stage and/or physiological condition [8]. In the rubber tree, the identification and characterization of expressed genes may improve our understanding of plant tolerance of biotic and abiotic stress, and the regulation of latex biosynthesis. Thus, the objectives of our study were to capture the transcriptional profile of a large variety of Hevea brasiliensis organs and tissues with a view to completing the available reference transcriptomes, then to identify in silico SNP and SSR markers and, lastly, develop the first SNPs markers in the rubber tree.

\section{Results and discussion}

\section{Transcriptome sequencing and assembling}

In order to capture the $H$. brasiliensis mass transcriptional profile with reduced sequencing costs, cDNA libraries were prepared from pooled RNA extracts of different tissues. Total RNA was extracted from 33 organs of the RRIM600 genotype and open-pollinated seedlings of RRIM600 (RRIM600 OPS library). Two main cDNA libraries were developed; one from a pool of RRIM600 RNA, and the other from tissues of RRIM600 OPS (Table 1). Together these runs produced 525,371 Roche /454 reads of lengths ranging from 40 to $873 \mathrm{bp}$ and a mean of $379 \mathrm{bp}$ (Figure 1A). After checking and trimming for quality scores (Figure 1B), adapters, PolyA/T tails and repetitive elements, 354,949 sequences accounting for 131,895,572 bases were inputted to the NEWBLER 2.7 assembler for contig generation (Table 2). NEWBLER assembly generated 19,708 contigs covering 13,328,059 bases; the N50 metric was $837 \mathrm{bp}$ (Figure 1C) and the mean GC content was $41.50 \%$. On average, each contig received $17.34 \mathrm{x}$ coverage ranging from 1 to 3,856 reads. A large number of contigs (90\%) resulted from the assembly of reads from the RRIM600 and RIM600 OPS libraries (Figure 1D). To overcome the problem of multiple contigs assembled from the same transcript, a scaffolding step by translational mapping (STM) was attempted. The joint assembly predict was built containing 18,867 sequences with an average length of $720 \mathrm{bp}$ ranging from 100 to $10,750 \mathrm{bp}$. De novo transcriptome assemblies may be substantially improved by the addition of a scaffolding step where the contigs belonging to a single transcript are ordered, orientated, and assembled [9]. Approximately 5\% of our assembly could be joined onto scaffolds, indicating a low redundancy of contigs. Also, our results of 18,867 scaffolds, N50= $837 \mathrm{bp}$, a mean length of contigs equal to $676 \mathrm{bp}$ and other metrics agreed with de novo sequencing from other plants $[10,11]$.

To verify the consistency of the assembly, a tBLASTx analysis was performed against the existing 9,860 EST sequences from $H$. brasiliensis deposited at the NCBI database by Chow, 2007 [12] generated by Sanger sequencing technology. The results indicated a coverage of $72 \%$ of the previously deposited Hevea ESTs available in NCBI (Figure 2A). Only 7\% presented less than 90\% similarity and only $4 \%$ had an E-value higher than 1e-40. The high similarity between the assembly and the deposited Hevea EST sequences suggested a consistent assembly and good coverage of the Hevea transcriptional landscape from all the tissues. 
Table 1 Organs and tissues used in the RRIM600 and RRIM600 OPS RNA extracts

\begin{tabular}{|c|c|c|c|}
\hline RRIM600 & $\mathrm{RIN}^{*}$ & RRIM600 OPS & RIN \\
\hline Apical meristem & 3.0 & Cotyledon in the seed (germination stage I) & 4.7 \\
\hline Leaflets stage A & 3.3 & Seedlings (germination stage II) & 5.3 \\
\hline Leaflets stage B2 & 1.8 & Stalk (germination stage III) & 3.7 \\
\hline Leaflets stage $C$ & 2.7 & Roots (germination stage III) & 3.7 \\
\hline Leaflets stage D & 2.5 & Seed (germination stage III) & 3.3 \\
\hline Petiole (Leaf stage B2) & 2.1 & Leaves (germination stage IV) & 1.6 \\
\hline Petiole (Leaf stage C) & 2.7 & Stalk (germination stage IV) & 3.5 \\
\hline Petiole (Leaflets stage D) & 2.7 & Roots (germination stage IV) & 3.4 \\
\hline Lignified stem & 3.0 & Seed (germination stage IV) & 3.3 \\
\hline Bark (trunk grafted with MDF180 crown) & 3.1 & Immature seeds with transparent endosperm & 2.2 \\
\hline Bark (trunk and crown of RRIM600) & 2.8 & Immature seeds with white endosperm & 1.2 \\
\hline Latex & 4.1 & Fertilized female flowers & 4.5 \\
\hline Raceme & 2.9 & & \\
\hline Male flowers, mature and immature & 3.7 & & \\
\hline Columns and wall of fruit lobes & 3.3 & & \\
\hline Fruit peel & 3.4 & & \\
\hline Peduncle & 2.8 & & \\
\hline Seed stage A endosperm & 1.2 & & \\
\hline
\end{tabular}

Triwitayakorn et al. [13] sequenced the expressed genome of the $H$. brasiliensis from the vegetative shoot apex of the rubber tree using the 454 platform, obtaining a larger number of reads $(2,311,497$ reads vs. 525,371 reads obtained here) with a lower average read length (294 vs. 379 bp) but with a similar number and size of the assembled sequences in 19,152 isogroups (theoretically, each one represents a single gene and its variations) ranging between 500 and $1000 \mathrm{bp}$, while our assembly produced 19,708 contigs with $676 \mathrm{bp}$ on average. Apart from the higher number of reads and the sampling of a few exclusive rubber tree tissues by Triwitayakorn et al. [13], the overall assembly process was very similar.

\section{Transcriptome Annotation}

Contigs were first annotated against a set of plant reference proteins $(399,458$ entries) by BLASTx. A total of 16,797 contigs identified matches with an E-value cut-off less than 1e-05 (Table 3). In an attempt to obtain a maximum of annotated contigs, a tBLASTx was carried out using the Plant Unique Transcript (PUT) database for Hevea brasiliensis ESTs with 4,896 entries in order to cover the transcripts that might lack protein annotation and could not be found in other databases. Subsequently, we performed a BLASTx against the Non-Redundant
NCBI protein database with the still unannotated contigs. In total, 2,911 non-annotated contigs were used as input and 299 contigs displayed a high score and a low e-value in the alignment with the Hevea PUT database (Table 3). The numbers presented by our Score (median 249.0), Identity (median 85\%) and E-Value statistics (median 1-e71) demonstrated a well performed assembly process since few non-matches $(\sim 12 \%)$ were observed at the end of entire BLAST annotation process. Our percentage of annotated sequences (88\%) was quite similar to the transcriptome of Xia et al. [14] who obtained 76\% of annotated sequences, of which $65.5 \%$ matched with Ricinus communis (vs. 68\% in this transcriptome) (Figure 2B). Differently, for the Hevea trancriptome of Triwitayakorn et al. [13], 48\% of sequences matched with Manihot esculenta, followed by $R$. communis (45\%).

To classify contigs correctly, a search for protein signatures was performed by InterPro scan on Open Reading Frames (ORFs) from each contig for Protein Domains, PANTHER (Protein Analysis Through Evolutionary Relationships) evidence, TIGR [Hidden Markov Models (HMMs) for protein sequence classification, and associated information] and Fingerprint (group of conserved motifs used to characterize a protein family) evidence, resulting in 3,521 IPR signatures; 367 protein family 


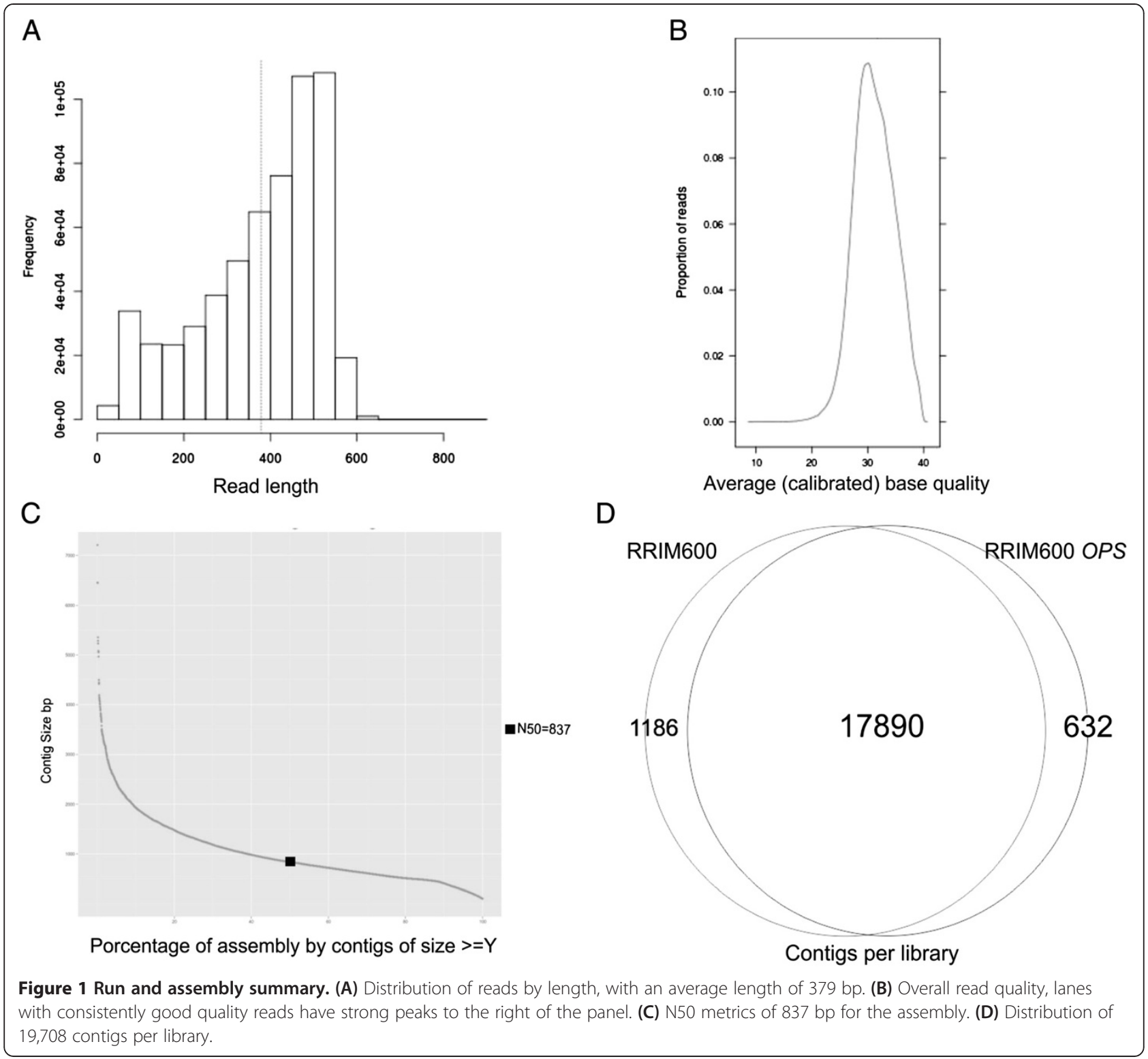

fingerprints; 2,655 protein domain families; 4,970 PANTHER families; 794 different structure families; and 419 TIGR families. These protein domains were associated with 46 GO terms (taking into consideration only those up to the second level of the GO hierarchical tree) belonging to the three GO categories (20 'biological processes', 11 'molecular functions' and 15 'cellular components') (Table 3). The GO terms 'cell part', 'binding activity', and 'metabolic processes' were the most represented classes in each GO category (Figure 3). Also, five genes (represented by 7 contigs) implicated in the mevalonate pathway (MVA) and consequently in natural rubber biosynthesis, were identified (Figure 4). COG analysis successfully classified 15,172 out of 19,708 sequences on 2,631 groups (Table 3). The orthology cluster described as 'unknown function' and general 'prediction only' accounted for $22 \%$ of annotations; another major clustering was related to translational and post translational functions

Table 2 Summary of Hevea brasiliensis transcriptome sequencing

\begin{tabular}{lllllll}
\hline Sample & Number of reads & Aligned reads & Number of contigs & Average contig size & N50 & Q40 plus* \\
\hline RRIM600 and RRIM600 OPS & 523,371 & $80.69 \%$ & 19,708 & 936 & 969 & $94.07 \%$ \\
\hline
\end{tabular}

* indicates the bases with a Phred-like consensus quality score of at least 40 (meaning a 1:10000 chance of the base being wrong). 

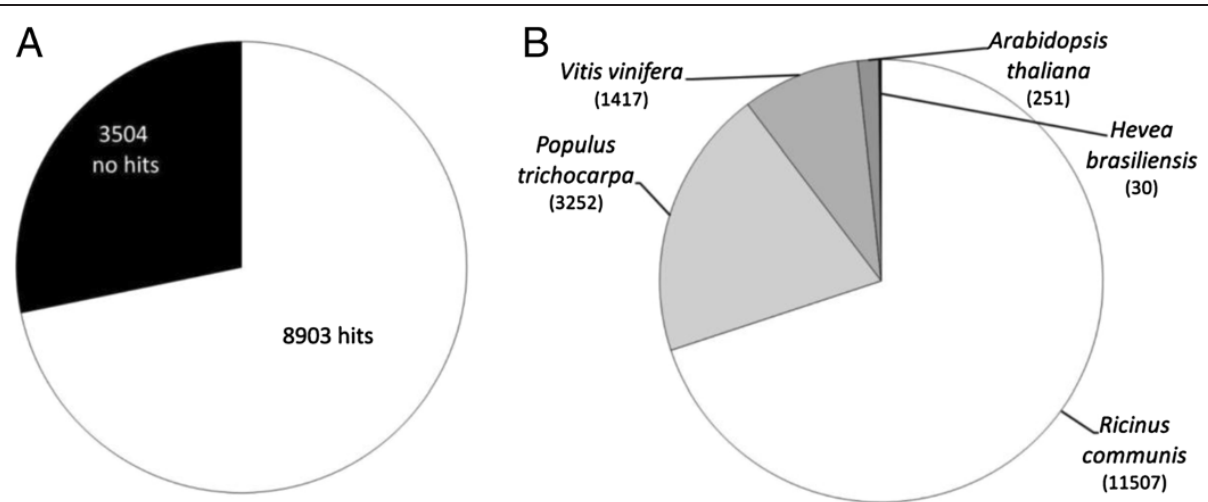

Figure 2 Comparison by BLASTx with 12,365 H brasiliensis sequences deposited in NCBI gene bank. (A) Matches; (B) Distribution for the top hits species.

(19\%) (Figure 5). The search for genes involved in metabolic pathways resulted in 5,059 contigs annotated in 134 KEGG orthologies (Table 3), distributed in 'Metabolic Processes', 'Enzyme Families', 'Genetic Information Processing', 'Environmental Information' 'Processing', and 'Cellular Processes'.

Transcriptome sequencing identified the genes (134) of the main active pathways confirmed by KEGG, covering the majority of enzymes in key processes such as 'plant hormone signal transduction' (39/41); 'plant-pathogen interaction' (27/50); and 'photosynthesis' (46/63) indicating that the effort to capture a global transcriptome landscape was achieved, demonstrated by the diversity of KEGG and GO annotation. Xia et al. (2011) [14] obtained 125 KEGG pathways, mainly distributed on 'metabolic pathways', 'spliceosome', and 'plant-pathogen interaction', while our most enriched pathways where 'Ribosome', 'Spliceosome', and 'RNA transport'.

\section{Comparisons with Hevea EST resources}

To verify the amount of new information provided by our assay, a tBLASTx was performed against the existing 39,034 EST sequences deposited in the NCBI public database related to Hevea brasiliensis (October, 2013). Of the 19,708 sequences, almost half of them $(8,792)$

Table 3 Summary of Hevea brasiliensis sequential annotation

\begin{tabular}{lc}
\hline Database & Annotated sequences \\
\hline Plant RefSeq protein & 16,797 \\
H. brasiliensis PUT & 299 \\
NR NCBI protein & 70 \\
GO & 8,725 \\
COG & 15,172 \\
KEGG & 5,059 \\
Not annotated & 2,542 \\
\hline
\end{tabular}

found no hits with an E-value cut-off of $10^{-5}$. Of these 1,164 were successfully annotated in the KEGG database, on 647 different KEGG orthologies, of which 356 were annotated as different enzymes belonging to metabolic pathways. Also, out of the 8,792 sequences, 3,949 were successfully annotated by searches for protein signatures on 2,095 different Interpro terms and 813 uniq GO terms (Figure 6). When ranked by uniqueness (1average semantic similarity of a term with all other terms; more uniq terms tended to be less dispensable) [15] the main biological process was the "mannose metabolic process", for cellular components it was the "cis-Golgi network" and for molecular functions "ammonium transmembrane transporter activity".

To gain an understanding of our transcript sets, comparing our contig set $(19,708$ sequences) with the read set originated from Triwitayakorn et al. [13], we identified 2,833 sequences with no correspondence, indicating new gene contributions from our libraries. Of those, 367 were exclusive sequences from the RRIM600 library and 564 originated from young tissues (RRIM600 OPS library). The 2,833 novel sequences were annotated on 56 GO terms in three ontologies, being 'cell part' as the most representative on the 'Cellular Component' term, 'Metabolic Process' for the 'Biological Process' term, and 'binding', for 'Molecular function'. Of the 2,833 new sequences identified in this study, 31 sequences were identified as genes related to plant cell dehydration processes. The most frequent was annotated as a Heat-shock proteins (Hsps)/chaperones with 21 occurrences.

\section{Screening for EST-SSR markers}

For many plant species, large numbers of expressed sequence tags (ESTs) have been generated although low numbers of validated EST-SSR and SNP markers are available for plants, especially for non-model plants. For the rubber tree, most of the available marker 


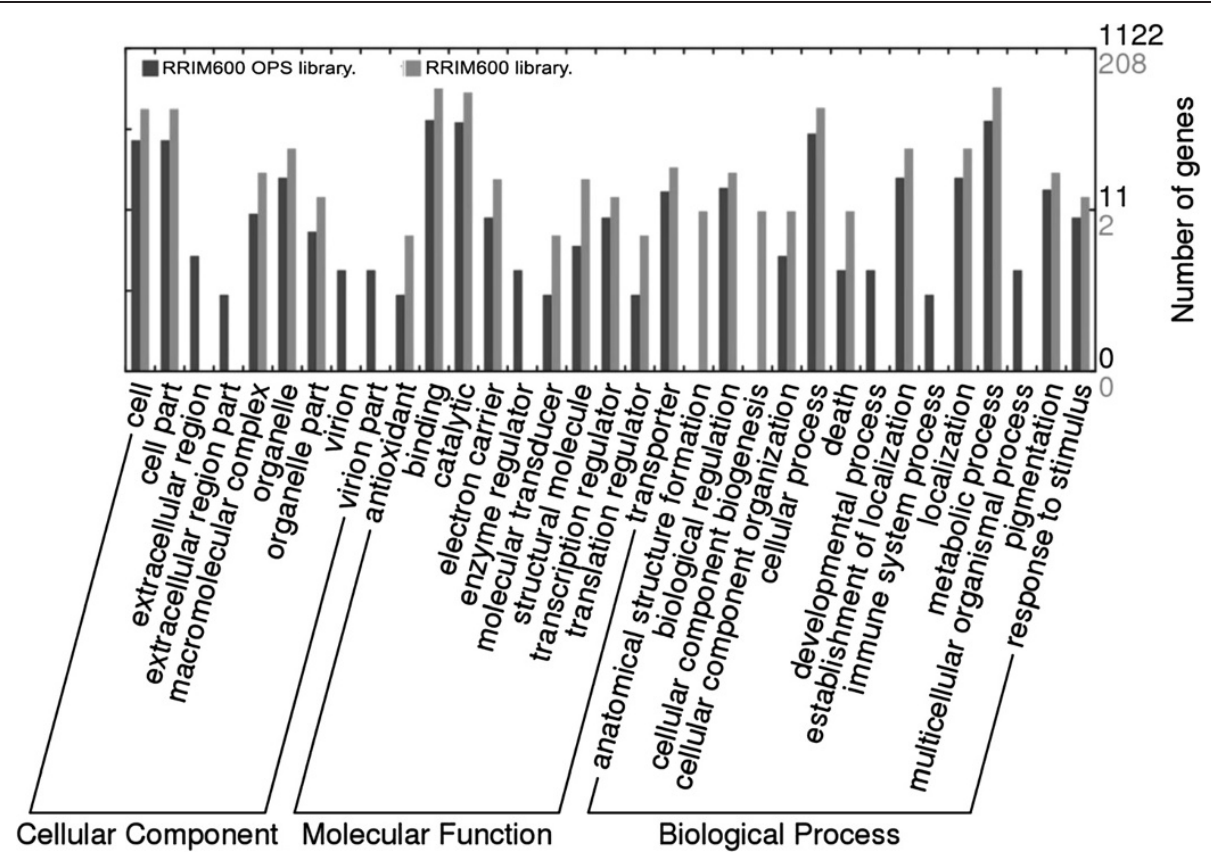

Figure 3 Summary of functional analysis by GO terms between the RRIM600 library and the RRIM600 OPS library divided into three main categories, "biological process", "cellular component" and "molecular function".

resources are isozyme, RFLP, AFLP and SSR markers [16]. SSR markers are today mainly obtained by a traditional method of SSR marker development, such as genomic-SSR hybrid screening and selective (or not) amplified microsatellite enrichment [17-21]. Recently, new EST-SSR markers were identified and proposed by several authors from transcriptomic data [13,22-24]. SSRs are typically co-dominant markers, proved to be useful in assessing population structure, determining relationships between closely related species and QTL mapping. Although SSR markers derived from expressed sequences are considered less informative due to DNA sequence conservation in the transcribed region [25], such markers are cost-effective and considered as functional sequences [19].

In our work, out of the 19,708 contigs examined, a total of 1,397 SSRs, formed by 187 different motifs, were identified in 1,148 sequences, with 152 contigs containing more than one SSR locus. The most frequent SSR type found was mononucleotide repeats with an average size of $12.56 \mathrm{bp}$ and $75 \mathrm{bp}$ repeats as the longest (Table 4). Feng et al. [22] searching for EST-SSRs in Hevea brasiliensis public databases successfully identified 799 loci on 10,829 EST sequences, one in every $2.25 \mathrm{~kb}$ of EST from the rubber tree. Here, we detected a lower SSR/Sequence frequency $(1 / 5.2 \mathrm{~kb})$, but the total number of identified SSR loci seemed to tally between the two studies, whereas the sequence analyzed/SSR discovery ratio was 14.1, similar to the value of 13.5 identified by $\mathrm{Yu}$ et al. [19]. The proportion of mono, di and trinucleotide repeats $(41 \%, 20 \%$ and $37 \%)$ was more balanced in our assay than in the Yu study $(45 \%, 42 \%, 11 \%)$ [19]. Triwitayakorn et al. [13], also found a lower distribution frequency $(1 / 3.3 \mathrm{~kb})$ than $\mathrm{Yu}$ et al. [19], but still higher than ours. Discrepancies between studies may come from differences in the methods, and the limitations of 454 technology when dealing with homopolymers.

\section{Screening for SNV markers}

Out of the 19,708 sequences obtained in this work, 889 contigs presented single nucleotide variants (SNVs) with more than $4 \mathrm{x}$ coverage, an average Q20 quality score, a minimum of 2 supporting reads at a position to call variants, ranging from 1 to 18 substitutions per single contig. These variations accounted for a total of 2,191 predicted biallelic SNVs on a total length of $13.3 \mathrm{Mb}$ of consensus sequences, corresponding to an average of one SNV every $6.0 \mathrm{~kb}$. This density was less than that reported by Pootakham [26] in the rubber tree (1 SNP/ $1.5 \mathrm{~kb}$ ), probably due to the greater stringency of our SNV detection parameters. Most of the detected and validated nucleotide variants were transitions (66.8\%), with transversions only accounting for 33.0\% (Figure 7), which was close to Pootakham's results [26]. Of those, 260 contigs presented nucleotide variation only on reads derived from the RRIM600 library totalizing 480 predicted SNVs for this particular library, while 362 contigs presented variations from consensus only on reads originating from the RRIM600 OPS library in a total of 666 predicted SNVs (Table 5). 


\section{TERPENOID BACKBONE BIOSYNTHESIS}

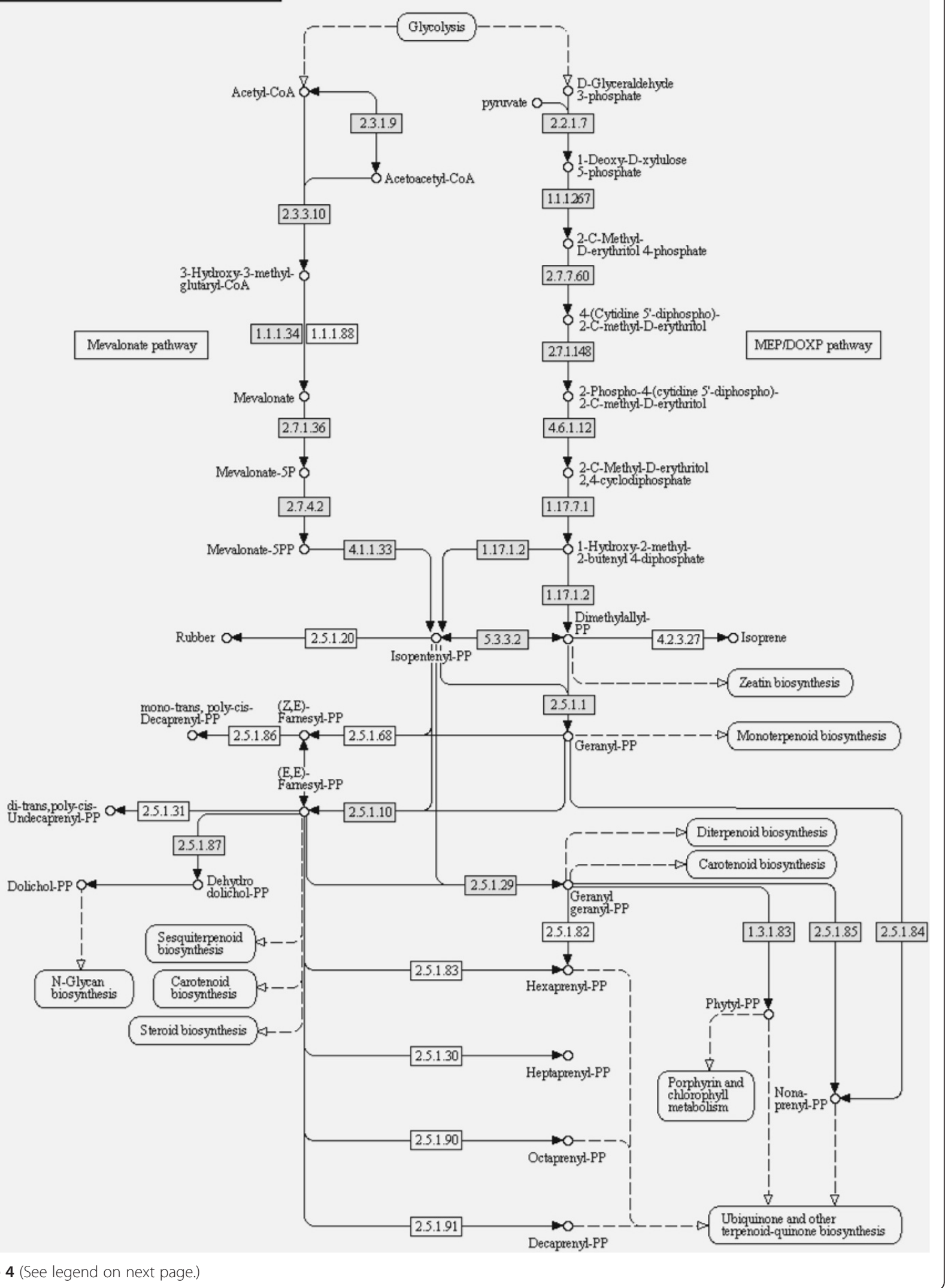

Figure 4 (See legend on next page.) 
Out of the 2,191 predicted SNVs there were 1,877 substitutions on CDS regions (predicted protein coding sequence) for 889 contigs, which resulted in 1,594 non-synonymous substitutions on 597 contigs. A total of 283 SNVs was observed on non-coding regions. Of all the detected variations, 1,594 were potential non-synonymous substitutions, accounting for $78 \%$ of all variations, indicating a high level of genetic variability.

Using a similar strategy, Barbazuk et al. [27] screened maize ESTs from shoot apical meristem by 454 searching for SNPs from two inbred lines and the data were anchored onto the sequence of the maize genome. An initial number of 36,000 putative SNPs was detected after the alignment of nearly 260,000 and 280,000 transcripts of both inbred lines. This figure fell to 7,000 putative SNPs after post-processing. Our strategy was different, using identification parameters with high stringency, allowing the prediction of only 2,191 SNVs, but with an average quality of Q20 and a coverage $\geq 4 x$. This strategy proved effective as demonstrated by the validation of 172 out of 191 putative SNPs (90\%) using an allelespecific amplification strategy. Similarly, Barbazuk et al. [27] identified variants exclusive to each inbred maize line and polymorphic sites with a different depth by inbred line. The validation of a subset of SNPs by PCR amplification and Sanger sequencing revealed a validation rate over $85 \%$. These data suggest that the computationally identified SNVs represented 'true' polymorphisms even for low ESTs-coverage regions, suggesting that 454-based transcriptome sequencing is an excellent method for the high-throughput acquisition of gene-associated SNPs. In the same way, Novaes et al. [28] studying multiple tissues and genotypes of Eucalyptus grandis, a non-model plant, on a 454 platform, sequenced and assembled $148 \mathrm{Mbp}$ ESTs from 1,024,251 reads identifying 23,742 SNPs, of which $83 \%$ were validated by Sanger sequencing in a sample of 337 SNPs.

From our data, non-synonymous SNVs accounted for $64 \%(1,211)$ of overall variations occurring in CDS regions. For non-synonymous changes it is not possible to directly determine how much the amino acid change will affect the protein structure, stability or localization. In Eukaryotes, changes in the protein isoelectric point (iP) may directly influence the localization and reactions of proteins, and it is reasonable to assume that alterations to the global protein iP may interfere in interactions

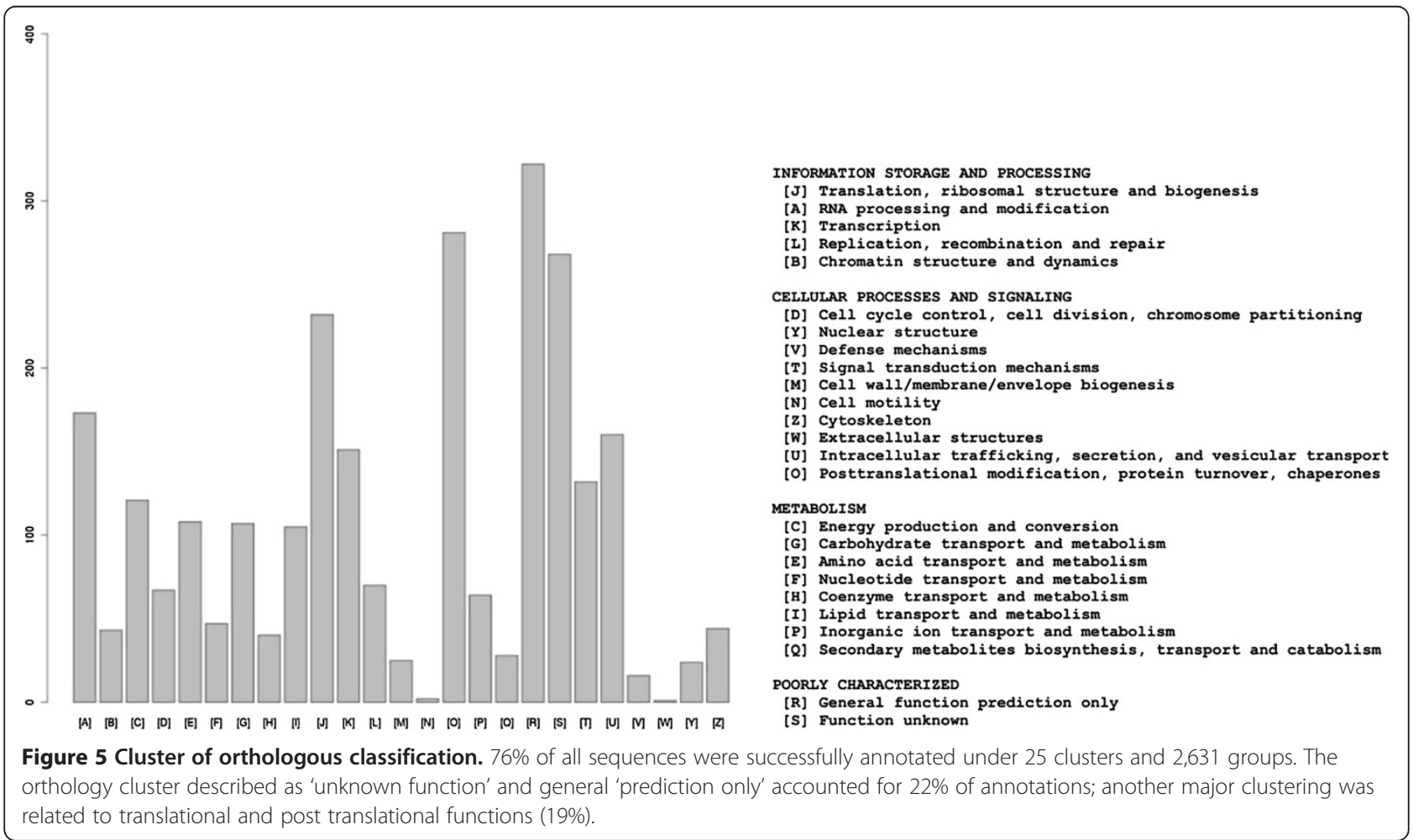




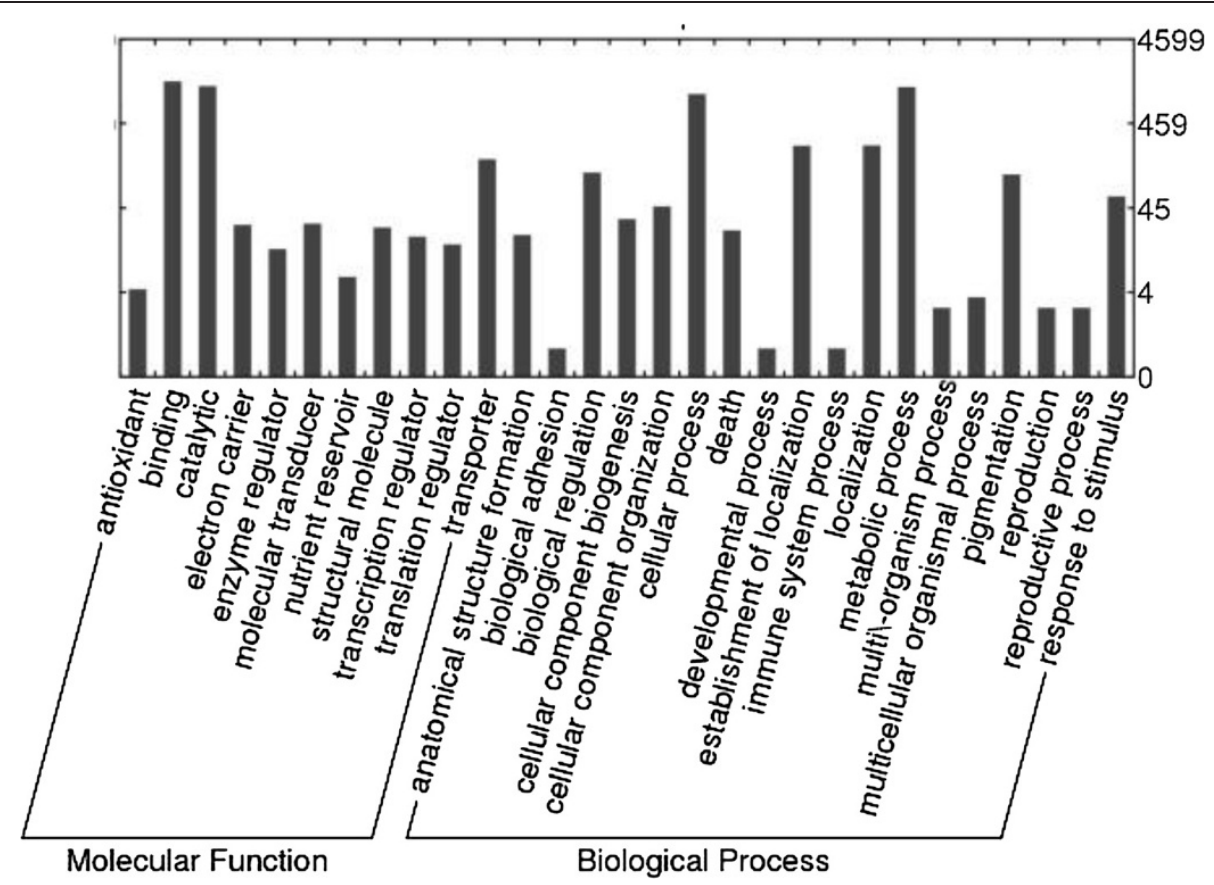

Figure $6 \mathrm{GO}$ terms histogram associated with "biological process" and "molecular function" for the 813 unique terms for the 8,792 novel genes.

between proteins and complexes. Alendé et al. [29], studying the evolution of iP over mammalian proteins, showed that insertions/deletions were the main reason for the shift in iP and suggested that shifts in iP might be related to the gain in additional activities, such as new interacting partners or preferences for orthologous or isoforms.

From the calculated iP and molecular weight $(\mathrm{Mw})$ for the mutated and non-mutated contigs that displayed non-synonymous mutation, the variation in iP ranged from -1.95 to 1.09 , and the $\mathrm{Mw}$ from $-97.11 \mathrm{kDa}$ to $66.08 \mathrm{kDa}$. A major alteration in iP was observed on a conserved hypothetical protein from Ricinus communis (alteration of -1.95 over original iP) annotated as a Ricinus communis conserved hypothetical protein, and 1.09 iP variation over the non-consensus sequence annotated as glycotransferase activity (GO: 0004579), KEEG (K12670) Glycan Biosynthesis. The characterization of $\mathrm{mW}$ and iP for the protein sequences translated from contigs with non-synonymous mutation showed that the $\mathrm{mW}$ from the mutated sequences was altered, but 250 sequences did not demonstrate any changes in iP values. Flegr [30] suggested that, since cell cytoplasm $\mathrm{pH}$ is stratified ranging from 6.4 to 7.2 in Eukaryotes, changes in the protein isoelectric point may directly influence the localization and reactions of proteins, and it is reasonable to assume that alterations to the global protein iP may interfere in interactions between proteins and complexes.

Substitutions outside coding regions (here 247 SNVs) are often linked to gene regulatory regions and may affect events, such as gene splicing, messenger RNA degradation or non-coding RNA sequences, and therefore usually called eSNP/V (expression single nucleotide polymorphism/variant), therefore becoming an interesting feature for biotechnological uses. Here, we were able to identify 2,191 mutations associated with 889 contigs.

Table 4 Distribution of identified SSRs according to SSR motif types and repeat numbers

\begin{tabular}{|c|c|c|c|c|c|c|c|c|c|c|c|c|c|}
\hline \multirow[t]{2}{*}{ Type of Repeat } & \multicolumn{4}{|c|}{ Number of repeat units } & \multirow[b]{2}{*}{9} & \multirow[b]{2}{*}{10} & \multirow[b]{2}{*}{11} & \multirow[b]{2}{*}{12} & \multirow[b]{2}{*}{13} & \multirow[b]{2}{*}{14} & \multirow[b]{2}{*}{15} & \multirow[b]{2}{*}{$>15$} & \multirow[b]{2}{*}{ Total } \\
\hline & 5 & 6 & 7 & 8 & & & & & & & & & \\
\hline Mononucleotide repeat & 0 & 0 & 0 & 0 & 0 & 176 & 115 & 62 & 50 & 27 & 26 & 111 & 567 \\
\hline Dinucleotide repeat & 0 & 110 & 38 & 36 & 22 & 16 & 12 & 7 & 13 & 4 & 2 & 18 & 278 \\
\hline Trinucleotide repeat & 271 & 117 & 45 & 29 & 18 & 16 & 5 & 2 & 5 & 0 & 1 & 1 & 510 \\
\hline Tetranucleotide repeat & 9 & 1 & 2 & 0 & 0 & 0 & 0 & 0 & 0 & 0 & 0 & 0 & 12 \\
\hline$\geq$ Pentanucleotide repeat & 22 & 5 & 0 & 2 & 1 & 0 & 0 & 0 & 0 & 0 & 0 & 0 & 30 \\
\hline
\end{tabular}




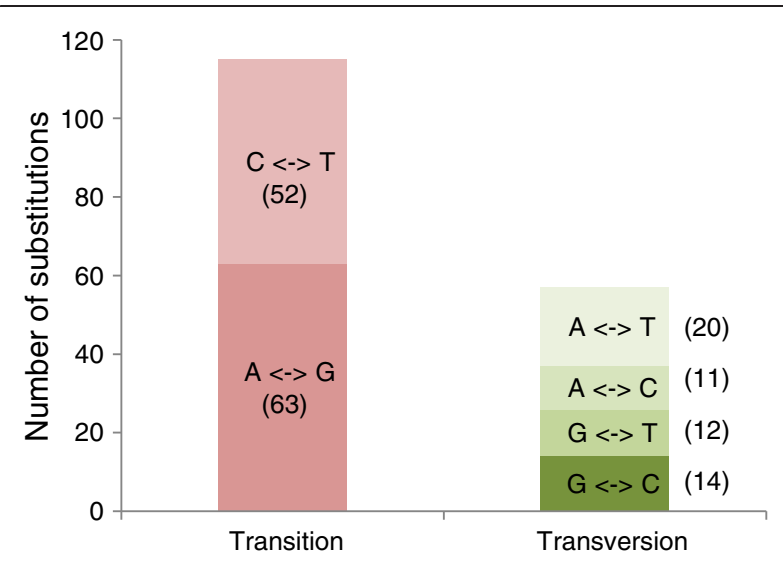

Figure 7 Classes of single nucleotide polymorphisms detected and validated in 454-derived EST contigs of Hevea brasiliensis. The number of each type of single-base substitutions is indicated in brackets.

The results obtained by Barbazuk et al. [27] and Novaes et al. [28] gave sufficient evidence about the reliability of the 454 sequencing platform for SNV identification in transcriptomic data, constituting an important feature for 454 data analysis.

\section{Analysis of genetic diversity}

Out of a set of 191 SNVs detected in silico, 172 SNPs were shown to be polymorphic among the 23 tested Hevea genotypes belonging to 3 species and resulting from different breeding programs (Table 6). PIC ranged between 0.04 and 0.38 , and heterozygosity varied from 0.04 to 0.5 (Additional file 1: Table S1). Ten SNPs displayed the same heterozygous combination for all the genotypes and were not included in the analysis of genetic diversity.
The tree (Figure 8), obtained from a dissimilarity matrix computed from allelic data of the 162 markers for each variety, gave a representation generally in accordance with the pedigree analysis (Table 6). The three genotypes which did not belong to the $H$. brasiliensis species (F4542, PUA8, PA31), were grouped together and were clearly distinct from most other $\mathrm{H}$. brasiliensis genotypes, as reported by Feng et al. [22] using 87 ESTSSR markers. IRCA130, PB235 and PB260 genotypes, presenting a common ancestral parent (PB5/51), were well located on the same branch. IRCA109 and PB217 genotypes bred from the same ancestral parents were positioned on close branches. Even more clearly, CMB104 and CMB114, two full-sib genotypes, were localized at a quite a similar distance from their parents IRCA109 and PFB5. PR107 and its progeny PR255 were located on the same branch.

It is the first time that a large number of SNPs have been developed in Hevea after the publication by Pootakham et al [21] of 10 SNPs. The result indicates that these 172 SNPs would be useful for rubber tree genetics and breeding studies. Being heterozygous for at least one of the parents of recently published Hevea genetic maps, most of these SNPs could easily contribute in the near future to enhancing the density of these SSR-based genetic maps: 102 SNPs could be mapped in the PB260 $\mathrm{x}$ Fx3899 map [16], 103 SNPs in the PR255 x PB217 map [31], 100 SNP in the PB260 x Fx2784 map [32] and 78 SNPs in the PB260 $x$ MDF180 map [33].

\section{Conclusions}

This is the first Hevea brasiliensis transcriptome release covering the main tissues extracted from both clonal plant materials and derived hybrid plant materials obtained by open-pollination, and the first to investigate and analyze Hevea brasiliensis SNVs. The results of

Table 5 Characterization of the 2,191 identified SNVs associated with 889 contigs

\begin{tabular}{|c|c|c|c|c|c|c|c|}
\hline \multirow[t]{2}{*}{ Nucleotide variation } & & \multirow{2}{*}{$\begin{array}{l}\text { Number } \\
\text { of SNVs }\end{array}$} & \multirow[t]{2}{*}{ Nonsense } & \multirow{2}{*}{$\begin{array}{l}\text { Number of } \\
\text { associated contigs }\end{array}$} & \multicolumn{3}{|l|}{ SNV position } \\
\hline & & & & & Coding sequence & UTR & $\begin{array}{l}\text { Non coding } \\
\text { sequence }\end{array}$ \\
\hline \multirow[t]{3}{*}{ Exclusive to the RRIM600 library } & Non-synonymous & 339 & 20 & 161 & 326 & 13 & 0 \\
\hline & Synonymous & 141 & & 99 & 98 & 27 & 16 \\
\hline & Total & 480 & & 260 & 424 & 40 & 16 \\
\hline \multirow[t]{4}{*}{ Exclusive to the RRIM600 OPS library } & Non-synonymous & 470 & 20 & 225 & 464 & 6 & 0 \\
\hline & Synonymous & 165 & & 115 & 90 & 45 & 30 \\
\hline & Non-determined* & 31 & & 22 & - & - & - \\
\hline & Total & 666 & & 362 & 554 & 51 & 30 \\
\hline \multirow[t]{3}{*}{ Common for both libraries } & Non-synonymous & 900 & 39 & 211 & 804 & 96 & 0 \\
\hline & Synonymous & 145 & & 56 & 95 & 31 & 19 \\
\hline & Total & 1.045 & & 267 & 899 & 127 & 19 \\
\hline
\end{tabular}

* No CDS 
Table 6 Genealogy of 23 Hevea spp. genotypes

\begin{tabular}{|c|c|c|}
\hline Genotype & Species & Genealogy \\
\hline F4542 & H. benthamiana & Primary clone \\
\hline PUA8 & H. pauciflora & Primary clone \\
\hline PA31 & H. pauciflora & Primary clone \\
\hline MDF180 & H. brasiliensis & Primary clone \\
\hline PFB5 & H. brasiliensis & Primary clone \\
\hline$F \times 2784$ & H. brasiliensis & Unknown \\
\hline PMB1 & H.brasiliensis & Primary clone \\
\hline FDR5788 & H.brasiliensis & Harbel8 x unknown \\
\hline RRIC100 & H.brasiliensis & RRIC52 x PB86 \\
\hline CMB104 & H.brasiliensis & IRCA109 x PFB5 \\
\hline CMB114 & H.brasiliensis & IRCA109 x PFB5 \\
\hline IRCA109 & H.brasiliensis & $\mathrm{PB} 5 / 51 \times \mathrm{RRIM} 600$ \\
\hline PB314 & H.brasiliensis & RRIM600 x PB235 \\
\hline RRIM600 & H.brasiliensis & Tjir1 x PB86 \\
\hline PR107 & H.brasiliensis & Primary clone \\
\hline PR255 & H.brasiliensis & Tjir1 x PR107 \\
\hline GT1 & H.brasiliensis & Primary clone \\
\hline IRCA130 & H.brasiliensis & $\mathrm{PB} 5 / 51 \times \mathrm{RRIM} 600$ \\
\hline PB235 & H.brasiliensis & $\mathrm{PB} 5 / 51 \times \mathrm{PBS} / 78$ \\
\hline PB260 & H.brasiliensis & $\mathrm{PB} 5 / 51 \times \mathrm{PB} 49$ \\
\hline PB217 & H.brasiliensis & $\mathrm{PB} 5 / 51 \times \mathrm{PB} 6 / 9$ \\
\hline Fx3899 & H. benthamiana $\times$ H.brasiliensis & F4542 $\times$ Avros 363 \\
\hline FDR5597 & H.brasiliensis & Harbel68 x TU42-525 \\
\hline
\end{tabular}

AVROS: Algemene Vereniging Rubberplanters Oostkust Sumatra; CMB: CIRAD Michelin Brazil; F: Ford; FDR: Firestone Dothidella Resistance; Fx: Ford Cross; IRCA: Institut de Recherches sur le Caoutchouc, Ivory Coast; MDF: Madre de Dios Firestone; PA and PUA: H. pauciflora; PB: Prang Besar, Malaysia; PMB1: Plantação Michelin da Bahia, Brazil; PFB: Pé Franco Brasileiro; RRIC: Rubber Research Institute Ceylon, Sri Lanka; RRIM: Rubber Research Institute of Malaysia; Tjir: Tjirandji, Indonesia; TU: Turrialba, Costa Rica.

similarity identification, diversity of transcript localization, and variety of predicted functions from the 19,708 contigs obtained by our study, associated with the variety of tissues sampled demonstrate a cohesive approach to capturing the transcriptional landscape of whole rubber tree physiology.

Moreover, the public availability of the sequences, functional annotation and the global variant analysis, as well as the sequencing of raw data to be released from this study will provide a source of valuable information for biotechnology assays and genetic improvement of rubber trees, an addition to be used for a reference transcriptome for further sequencing projects.

As an allogamous plant with a recent history of selection, most of Hevea genotypes are highly heterozygous, opening the way for the development of a huge number of SNP markers.

\section{Methods}

Plant material

Tissues samples of $H$. brasiliensis from the RRIM600 cultivar, were collected at the E. Michelin Plantation in Itiquira (Mato Grosso state, Brazil) and at the Michelin Plantation in Ituberá (Bahia state, Brazil). Samples of male and female flowers, fruits, bark and latex from adult RRIM600 trees were collected at the E. Michelin Plantation and conserved in RNAlater (Life Technologies Carlsbad, CA, USA) until RNA extraction. Samples of stalks, petioles and leaves from grafted plants of RRIM600 and tissues (radicle, hypocotyl, epicotyl, albumen, cotyledon, leaves) from germinated seedlings of open-pollinated RRIM600 seeds were collected from a greenhouse at the Michelin Plantation in Ituberá. The tissue samples were stored in liquid nitrogen.

\section{Total RNA isolation and CDNA synthesis}

Total RNA was isolated from $1 \mathrm{~g}$ of ground conserved tissue and extracted as described by Morcillo et al. (2006) [34]. RNA integrity was evaluated using a 2100 Bioanalyzer (Agilent Technologies, Santa Clara, CA, USA). Before mRNA purification, 18 RNA samples of RRIM600 tissues and 12 extracts of RRIM600 OPS (open-pollinated seedlings) were pooled. Poly(A) RNA was isolated from these two pools with oligo beads (dT) from the PolyATtract mRNA kit (Promega, Madison, WI, USA).

Following isolation, the mRNAs were fragmented using a $0.1 \mathrm{M}$ zinc chloride solution in $0.1 \mathrm{M}$ Tris- $\mathrm{HCl}$ pH7.0. Using these shorter fragments as templates, the first-strand cDNAs were synthesized using Roche random primers and the AMV reverse transcriptase from the cDNA Synthesis system and the GS Rapid Library kits (Roche Applied Science, Mannheim, Germany). Sequencing was carried out on a Roche/454 GS-FLX (Titanium) pyrosequencing platform.

\section{4 sequencing and assembly of cDNA libraries}

The cDNA libraries were amplified with emulsion PCR Lib-L (Roche Applied Science) and sequenced using the XLR70 sequencing kit and a $70 \times 75 \mathrm{~mm}$ PicoTiterPlate (Roche Applied Science). Each library was sequenced in one region of the PicoTiterPlate.

All of the $H$. brasiliensis cDNA data were first filtered by quality scores, presence of adapters, PolyA/T tails and repetitive elements using preprocess.pl Perl script from est2Assembly [35], and then assembled into contigs using the Newbler de novo assembler algorithm of the gsassembler (Newbler version 2.7, Roche 454). Reads and assembled contigs were analyzed using $\mathrm{R}$ programming version 2.13.2 [36]. Scaffolding assembly was carried out by STM (Scaffolding using Translation Mapping) [09]. The STM method relies on the assumption that the gene set of the 


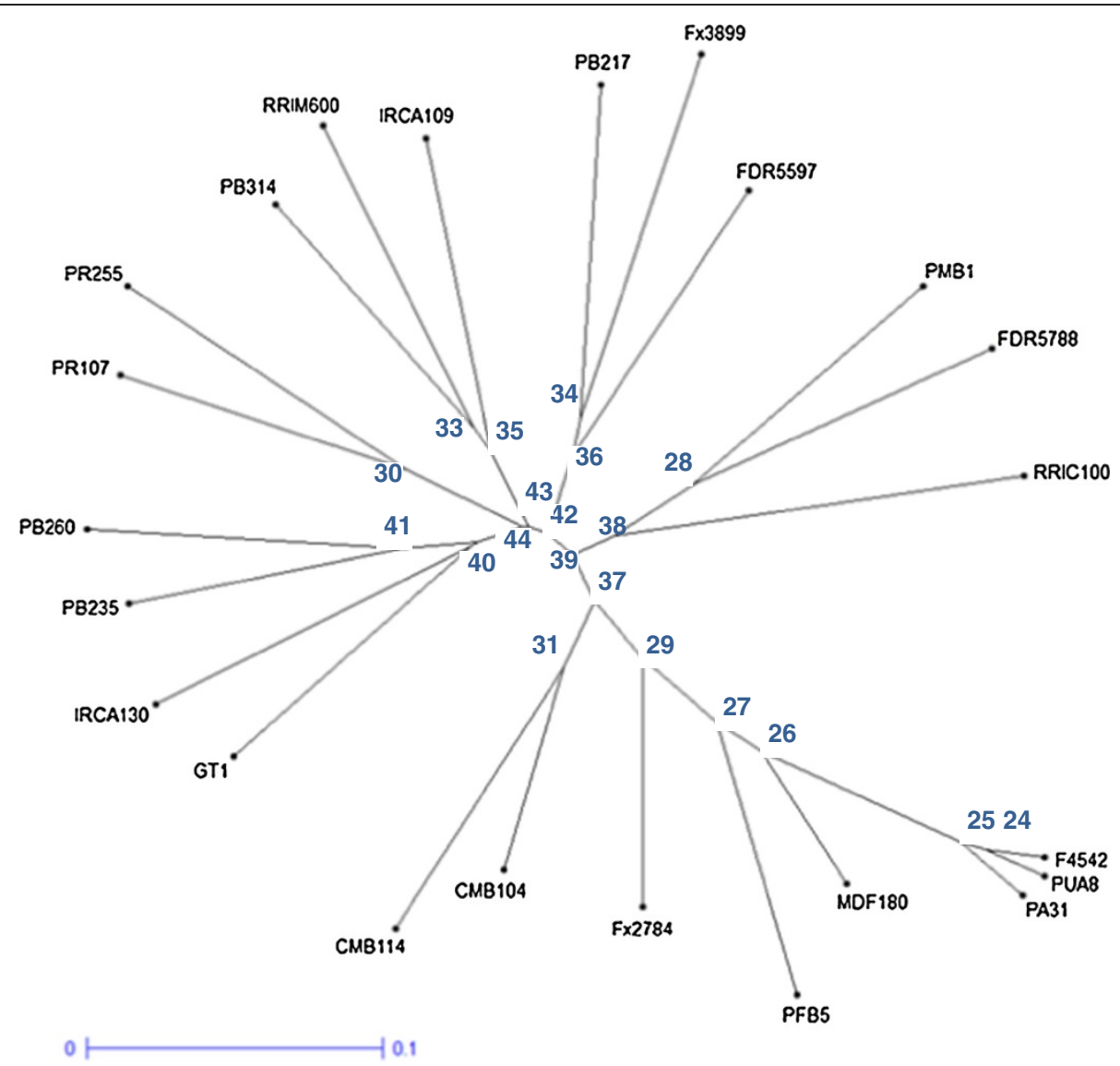

Figure 8 Neighbor Joining tree illustrating relashionships between 23 Hevea spp. genotypes analyzed with 162 SNP loci. Boostrap values (1000 replicates) are shown next to the branches.

reference proteome, which will serve as a template for joining contigs into scaffolds, is sufficiently similar, and, in this way, all translated contigs matching a same reference protein can be assembled into a scaffold [09]. We used the Ricinus communis Protein sequence (amino acid translation) release $0.1[37]$

\section{Annotation, classification and comparison of assembled sequences}

Contigs were compared to the set of proteome references by the BLAST algorithm (at an E-value threshold $10^{-5}$ ) against NCBI RefSeq, Plant Protein Database [38], H. brasiliensis assembled unique transcripts (PUT) of PlantGDB [39] and the complete NCBI nr database. We preferentially annotated contigs (with best BLAST hits) based first on similarity to Plant Protein RefSeq, then based on $H$. brasiliensis PUT nucleotides, and finally on NonRedundant of nucleotides from the NCBI database. InterProScan version 4.8 was used for Gene Ontology and InterPro annotation [40] to connect Hevea transcript contigs with known gene ontology annotations. WEGO [41] software was used to perform $\mathrm{GO}$ annotation analysis and for plotting GO annotations. Also, attempting to phylogenetically classify the sequences, a BLAST using the Cluster of Orthologous Groups database was performed.

To gain an understanding of our set of transcripts mapping performed by GS Reference Mapper (Newbler version 2.7, Roche 454) against currently available $H$. brasiliensis sequences was carried out using the 2,311,497 reads generated by the Triwitayakorn et al. [13], obtained by sequencing $H$. brasiliensis shoot apex of the RRIM600 genotype, 30,094 Hevea brasiliensis EST sequences available in the NCBI database, including 9,860 ESTs (accession No EC600050-EC609910) from RRIM600 latex deposited in NCBI by Chow et al. [12].

For putative genes involved in the metabolic pathway, a KEGG annotation was performed using KAAS (KEGG Automatic Annotation Server) [42].

\section{Identification of Single Nucleotide Variants (SNVs) and Simple Sequence Repeat (SSR) loci}

To detect nucleotide variants over the contigs, an alignment between reads and the contigs generated by Newbler as a reference was performed using the Burrows-Wheeler Aligner for long reads (BWA-SW) [43]. The results were used as input for the Bioconductor [44] Rsamtools 
version 1.6.0 package to obtain the possible nucleotide variants with a cut-off coverage of $4 x$, a threshold of 2 variants in the position and a base call quality cut-off of the PHRED score $\mathrm{Q} 20$ on average, where $\mathrm{Q}=-10$ $\log 10 \mathrm{P}$, and the score stands for the probability of a wrong base being called.

To check wether or not SNV was responsible for a non-synonym alteration in the amino acid composition from the contig, a gene prediction analysis was carried out by the GlimmerHMM Eukaryotic Gene-Finding System [45] using the Arabidopsis thaliana training model in an attempt to identify the Protein Coding Sequence, for correct verification of the SNV substitution type made by the R/Bioconductor script.

Searches for SSRs from the contig data set were performed by Microsatellite Identification Tool (MISA) version 1.0 [46]. The definition of microsatellites (unit size/ minimum number of repeats) was set as mononucleotides repeats if the same nucleotide was repeated at least 10 times $(1 / 10)$, di $(2 / 6)$, tri $(3 / 5)$, tetra $(4 / 5)$, penta $(5 / 5)$, or hexanucleotides (6/5), and 100 as the maximum number of bases interrupting two SSRs in a compound microsatellite (microsatellites consisted of more than a single repeat type).

\section{Protein characterization}

The molecular weight and the isoelectric point analyses for proteins were performed by EMBOSS version 6.4.0 [47] and the generated output analyzed by $\mathrm{R}$ programming language.

\section{Development of SNP markers}

The 191 detected SNPs were validated using KASP genotyping chemistry (KBioscience Ltd., Hoddesdon, UK) on 23 Hevea genotypes including different species ( $H$. brasiliensis, benthamiana and pauciflora) and related genotypes (Table 6). Rubber tree total genomic DNA was extracted from fresh leaves following a previously described method [48]. For each SNV position, three primers were designed in a region of +50 and $-50 \mathrm{pb}$ around the nucleotide variation by KBioscience with PrimerPicker [49]. The 191 Assay Mixes contained two allele-specific forward primers $(12 \mu \mathrm{M})$ able to anchor specifically to the 3 ' position in the nucleotide variant, and a reverse primer $(30 \mu \mathrm{M})$. Genotyping was performed using the traditional KASP genotyping chemistry on a LightCycler 480 II (Roche) using a 384-well plate. The PCR reactions were carried out in $4 \mu \mathrm{L}$ containing 2 ng of genomic DNA, $2 \mu \mathrm{L}$ Master MIX 2x, $2.2 \mathrm{mM}$ $\mathrm{MgCl}_{2}$ and $0.055 \mu \mathrm{L}$ Assay Mix. One denaturation cycle was performed at $95^{\circ} \mathrm{C}$ for $15 \mathrm{~min}$, prior to 10 denaturation cycles at $94^{\circ} \mathrm{C}$ for $20 \mathrm{~s}$, annealing at $65^{\circ} \mathrm{C}$ for $1 \mathrm{~min}$ (- $0.8^{\circ} \mathrm{C} /$ cycle), followed by 40 denaturation cycles for $20 \mathrm{~s}$, annealing at $57^{\circ} \mathrm{C}$ for $1 \mathrm{~min}$. The end point fluorescence signal was measured and plotted on two axes. All genotype calls were manually checked and ambiguous data points that failed to cluster were scored as missing data. Each nucleotide variant was scored as allelic data $(A=1, C=2, G=3, T=4$, not determined data $=0$ ). These data were used to calculate a genetic dissimilarity matrix using the simple matching dissimilarity index $\left(\mathrm{d}_{\mathrm{ij}}\right)$ between pairs of accessions (units) [50].

$$
d_{i j}=1-\frac{1}{L} \sum_{l=1}^{L} \frac{m_{l}}{2}
$$

where $d_{i j}$ represents the dissimilarity between units $i$ and $\mathrm{j}, \mathrm{L}$ represents the number of loci, and $\mathrm{m}_{1}$ represents the number of matching alleles between $i$ and $j$ for locus $l$. From the dissimilarity matrix, a Neighbor-Joining tree [51] was computed using the DARwin software version 5.0.158 (Dissimilarity Analysis and Representation for Windows, http://darwin.cirad.fr/darwin [50]. Branch robustness was tested using 1000 bootstraps.

\section{Additional file}

Additional file 1: Table S1. Characteristics of SNP loci developed in Hevea. The 454-data generated can be accessed and downloaded at http://scarecrow.fmrp.usp.br/heveabr/.

\section{Competing interests}

The authors declare that they have no competing interests.

\section{Authors' contributions}

LRS and DGP worked on assembly, annotation, pathway analysis, screening for molecular markers. LRS and DG wrote the manuscript. DMK and DG generated the RNA libraries. DG, MFN, LGPA, VRR, MG, and ALG performed the raw data generation. RR, VL and DG developed the SNPS. AF, JCMC, ATRV, WASJ, LLC and DG designed the study. All the authors read and approved the final manuscript.

\section{Acknowledgements}

This work was supported by CNPq (National Council for Scientific and Technological Development) PROSUL process 490748/2008-2 and CAPES for fellowship. The authors thank the FUNDERP (Fundação Hemocentro de Ribeirão Preto) and the BIT (Bioinformatics Laboratory) for technological support and Peter Biggins for reviewing the text of this manuscript.

\section{Author details}

'Departamento de Genética/FMRP/USP, Laboratório de Genética Molecular e Bioinformática, Rua Tenente Catão Roxo, 2501, CEP 14.051- 140 Ribeirão Preto, São Paulo, Brazil. 'Laboratório de Genômica e Biologia Molecular, Universidade Estadual de Santa Cruz, Rod. Ilhéus-Itabuna BR 415, Km 16, Ilhéus, Bahia CEP 45.662-000, Brazil. ${ }^{3}$ CIRAD, BIOS, UMR-AGAP, TA A96/03, Av. Agropolis, 34398 Montpellier, France. 'Laboratório Nacional de Computação Científica, av. Getulio Vargas, n³33 Quitandinha, CEP 25.651-075 Petrópolis, Rio de Janeiro, Brazil. ${ }^{5}$ Centro de Energia Nuclear na Agricultura/Universidade de São Paulo, Piracicaba, Brazil. ${ }^{6}$ ESALQ/USP, Piracicaba, Brazil.

Received: 12 March 2013 Accepted: 24 March 2014

Published: 26 March 2014

\section{References}

1. ter Steege H, Pitman NCA, Sabatier D, Baraloto C, Salomão RP, Guevara JE, Phillips OL, Castilho CV, Magnusson WE, Molino J-F, Monteagudo A, Vargas PN, Montero JC, Feldpausch RT, Coronado ENH, Killeen TJ, Mostacedo B, 
Vasquez R, Assis RL, Terborgh J, Wittmann F, Andrade A, Laurance WF, Laurance SGW, Marimon BS, Marimon B-H Jr, Vieira ICG, Amaral IL, Brienen $\mathrm{R}$, Castellanos $\mathrm{H}$, et al: Hyperdominance in the amazonian tree flora. Science 2013, 342. doi:10.1126/science.1243092.

2. da Costa RB, de Resende MDV, Gonçalves PDES, Chichorro JF, Roa RAR: Variabilidade genética e seleção para caracteres de crescimento da seringueira. Bragantia [online] 2008, 67:299-305.

3. Mooibroek $\mathrm{H}$, Cornish $\mathrm{K}$ : Alternative sources of natural rubber. Appl Microbiol Biotechnol 2000, 53:355-365.

4. Priyadarshan PM, Goncalves PDS: Hevea gene pool for breeding. Genet Resour Crop Evol 2003, 50:101-114.

5. Toledo PEN: In Seringueira. MG. EPAMIG: Viçosa; 2008.

6. Rivano F, Mattos CRR, Cardoso SEA, Martinez M, Cevallos V, Le Guen V, Garcia D: Breeding Hevea brasiliensis for yield, growth and SALB resistance for high disease environments. Ind Crop Prod 2013, 44:659-670.

7. Alvarenga AP, Carmo CAF: In Seringueira. MG. EPAMIG: Viçosa; 2008.

8. Wang Z, Gerstein M, Snyder M: RNA-Seq: a revolutionary tool for transcriptomics. Nat Rev Genet 2009, 10:57-63.

9. Surget-Groba Y, Montoya-Burgos Jl: Optimization of de novo transcriptome assembly from next-generation sequencing data. Genome Res 2010, 20:1432-1440.

10. Parchman TL, Geist KS, Grahnen J a, Benkman CW, Buerkle CA: Transcriptome sequencing in an ecologically important tree species: assembly, annotation, and marker discovery. BMC Genomics 2010, 11:180.

11. Ness RW, Siol M, Barrett SC: De novo sequence assembly and characterization of the floral transcriptome in cross- and self-fertilizing plants. BMC Genomics 2011, 12:298.

12. Chow K-S, Wan K-L, Isa MNM, Bahari A, Tan S-H, Harikrishna K, Yeang H-Y: Insights into rubber biosynthesis from transcriptome analysis of Hevea brasiliensis latex. J Exp Bot 2007, 58:2429-2440.

13. Triwitayakorn K, Chatkulkawin P, Kanjanawattanawong S, Sraphet S, Yoocha T, Sangsrakru D, Chanprasert J, Ngamphiw C, Jomchai N, Therawattanasuk K, Tangphatsornruang S: Transcriptome sequencing of Hevea brasiliensis for development of Microsatellite Markers and Construction of a Genetic Linkage Map. DNA Research: an international journal for rapid publication of reports on genes and genomes 2011, 18:471-482.

14. Xia Z, Xu H, Zhai J, Li D, Luo H, He C, Huang X: RNA-Seq analysis and de novo transcriptome assembly of Hevea brasiliensis. Plant Mol Biol 2011, 77:299-308.

15. Supek F, Bošnjak M, Škunca N, Šmuc T: REVIGO summarizes and visualizes long lists of gene ontology terms. PLOS ONE 2011, 6(7):e21800.

16. Lespinasse D, Rodier-Goud M, Grivet L, Leconte A, Legnate $H$, Seguin M: A saturated genetic map of rubber tree (Hevea spp.) based on RFLP, AFLP, microsatellite, and isozyme markers. Theor Appl Genet 2000, 100:127-138.

17. Saha T, Bindu Roy C, Nazeer MA: Microsatellite variability and its use in the characterization of cultivated clones of Hevea brasiliensis. Plant Breed 2005, 124:86-92

18. Le Guen V, Gay C, Xiong TC, Souza LM, Rodier-Goud M, Seguin M: Development and characterization of 296 new polymorphic microsatellite markers for rubber tree (Hevea brasiliensis). Plant Breed 2011, 130:294-296.

19. Yu F, Wang B-H, Feng S-P, Wang J-Y, Li W-G, Wu Y-T: Development, characterization, and cross-species/genera transferability of SSR markers for rubber tree (Hevea brasiliensis). Plant Cell Rep 2011, 30:335-344.

20. Mantello CC, Suzuki FI, Souza LM, Gonçalves PS, Souza AP: Microsatellite marker development for the rubber tree (Hevea brasiliensis) characterization and cross-amplification in wild Hevea species. BMC Res Notes 2012, 5:329. doi: 10.1186/1756-0500-5-329.

21. Pootakham W, Chanprasert J, Jomchai N, Sangsrakru D, Yoocha T, Therawattanasuk K, Tangphatsornruang S: Development of genomicderived simple sequence repeat markers in Hevea brasiliensis from 454 genome shotgun sequences. Plant Breed 2012, 131:555-562.

22. Feng SP, Li WG, Huang HS, Wang JY, Wu YT: Development, characterization and cross-species/genera transferability of EST-SSR markers for rubber tree (Hevea brasiliensis). Mol Breed 2009, 23:85-97.

23. Li D, Deng Z, Qin B, Liu X, Men Z: De novo assembly and characterization of bark transcriptome using Illumina sequencing and development of EST-SSR markers in rubber tree (Hevea brasiliensis Muell. Arg.). BMC Genomics 2012, 13:192.

24. Cubry P, Pujade-Renaud V, Garcia D, Espeout S, Le Guen V, Granet F, Seguin M: Development and characterization of a new set of 164 polymorphic
EST-SSR markers for diversity and breeding studies in rubber tree (Hevea brasiliensis Müll.Arg.). Plant Breed 2014. doi:10.1111/pbr.

25. Bouck A, Vision T: The molecular ecologist's guide to expressed sequence tags. Mol Ecol 2007, 16:907-924.

26. Pootakham W, Chanprasert J, Jomchai N, Sangsrakru D, Yoocha T, Tragoonrung S, Tangphatsornruang S: Single nucleotide polymorphism marker development in rubber tree, Hevea brasiliensis (Euphorbiaceae). Am J Bot 2011, 98(11):e337-e338.

27. Barbazuk WB, Emrich SJ, Chen HD, Li L, Schnable PS: SNP discovery via 454 transcriptome sequencing. J Plant Cell Mol Biol 2007, 51:910-918.

28. Novaes E, Drost DR, Farmerie WG, Pappas GJ, Grattapaglia D, Sederoff RR, Kirst M: High-throughput gene and SNP discovery in Eucalyptus grandis, an uncharacterized genome. BMC Genomics 2008, 9:312.

29. Alendé N, Nielsen JE, Shields DC, Khaldi N: Evolution of the isoelectric point of mammalian proteins as a consequence of indels and adaptive evolution. Proteins 2011, 79:1635-1648.

30. Flegr J: A possible role of intracellular isoelectric focusing in the evolution of eukaryotic cells and multicellular organisms. J Mol Evol 2009, 69:444-451.

31. Souza LM, Gazaffi R, Mantello CC, Silva CC, Garcia D, Le Guen V, Cardoso SEA, Garcia AAF, Souza AP: QTL Mapping of growth-related traits in a full-sib family of rubber tree (Hevea brasiliensis) evaluated in a sub-tropical climate. PLOS ONE 2013, 8(4):e61238.

32. Le Guen V, Garcia D, Mattos CRR, Fouet O, Doaré F, Condina V, Seguin M: A newly identified locus controls complete resistance to Microcyclus ulei in the Fx2784 rubber clone. Tree Genet Genomes 2013, 9:805-812.

33. Le Guen V, Garcia D, Doaré F, Mattos CRR, Condina V, Couturier C, Chambon A, Weber C, Espéout S, Seguin M: A rubber tree's durable resistance to Microcyclus ulei is conferred by a qualitative gene and a major quantitative resistance factor. Tree Genet Genomes 2011, 7:877-889.

34. Morcillo F, Gagneur C, Adam H, Richaud F, Singh R, Cheah S-C, Rival A Duval Y, Tregear JW: Somaclonal variation in micropropagated oil palm. Characterization of two novel genes with enhanced expression in epigenetically abnormal cell lines and in response to auxin. Tree Physiol 2006, 26:585-594.

35. Papanicolaou A, Stierli R, Ffrench-Constant RH, Heckel DG: Next generation transcriptomes for next generation genomes using est2assembly. BMC Bioinforma 2009, 10:447.

36. R Core Team R: R: A Language and Environment for Statistical Computing. Vienna, Austria: R Foundation for Statistical Computing; 2013. URL http://www.R-project.org

37. J Craig Venter institute: J Craig Venter institute. http://castorbean.jcvi.org/.

38. Pruitt KD, Tatusova T, Maglott DR: NCBI Reference Sequence (RefSeq): a curated non-redundant sequence database of genomes, transcripts and proteins. Nucleic Acids Res 2005, 33(Database issue):D501-D504.

39. Dong Q, Schlueter SD, Brendel V: PlantGDB, plant genome database and analysis tools. Nucleic Acids Res 2004, 32(Database issue):D354-D359.

40. Zdobnov EM, Apweiler R: InterProScan-an integration platform for the signature-recognition methods in InterPro. Bioinformatics 2001 17:847-848

41. Ye J, Fang L, Zheng H, Zhang Y, Chen J, Zhang Z, Wang J, Li S, Li R, Bolund L, Wang J: WEGO: a web tool for plotting GO annotations. Nucleic Acids Res 2006, 34(Web Server issue):W293-W297.

42. Moriya $Y$, Itoh M, Okuda S, Yoshizawa AC, Kanehisa M: KAAS: an automatic genome annotation and pathway reconstruction server. Nucleic Acids Res 2007, 35(Web Server issue):W182-W185.

43. Li H, Durbin R: Fast and accurate short read alignment with BurrowsWheeler transform. Bioinformatics 2009, 25:1754-1760.

44. Gentleman RC, Carey VJ, Bates DM, Bolstad B, Dettling M, Dudoit S, Ellis B, Gautier L, Ge Y, Gentry J, Hornik K, Hothorn T, Huber W, lacus S, Irizarry R, Leisch F, Li C, Maechler M, Rossini AJ, Sawitzki G, Smith C, Smyth G, Tierney L, Yang JY, Zhang J: Bioconductor: open software development for computational biology and bioinformatics. Genome Biol 2004, 5:R80.

45. Majoros WH, Pertea M, Salzberg SL: TigrScan and GlimmerHMM: two open source ab initio eukaryotic gene-finders. Bioinformatics 2004, 20:2878-2879.

46. MISA - MIcroSAtellite Identification Tool. http://pgrc.ipk-gatersleben.de/misa/

47. Rice P, Longden I, Bleasby A: EMBOSS: the European Molecular Biology Open Software Suite. Trends Genet 2000, 16:276-277. 
48. Le Guen V, Doaré F, Weber C, Seguin M: Genetic structure of Amazonian populations of Hevea brasiliensis is shaped by hydrographical network and isolation by distance. Tree Genet Genomes 2009, 5:673-683.

49. KBioscience: PrimerPicker Lite for KASPar v.0.26. Hoddesdon: KBioscience Ltd; 2009.

50. Perrier X, Jacquemoud-Collet JP: DARwin software. 2006. http://darwin.cirad.fr/.

51. Saitou N, Nei M: The Neighbor-Joining method: a new method for reconstructing phylogenetic trees. Mol Biol Evol 1987, 4(4):406-425.

doi:10.1186/1471-2164-15-236

Cite this article as: Salgado et al.: De novo transcriptome analysis of Hevea brasiliensis tissues by RNA-seq and screening for molecular markers. BMC Genomics 2014 15:236.

\section{Submit your next manuscript to BioMed Central and take full advantage of:}

- Convenient online submission

- Thorough peer review

- No space constraints or color figure charges

- Immediate publication on acceptance

- Inclusion in PubMed, CAS, Scopus and Google Scholar

- Research which is freely available for redistribution 